\title{
Spinal Cord Sarcoma
}

National Cancer Institute

\section{Source}

National Cancer Institute. Spinal Cord Sarcoma. NCI Thesaurus. Code C5152.

A sarcoma that arises from the spinal cord. 